\title{
Service users with experience of poverty as institutional entrepreneurs in public services in Belgium: An institutional theory perspective on policy implementation
}

\section{Introduction}

In the European context, a contemporary and vital issue concerns the modes in which policies are implemented in public service delivery (see Barrett 2004). As Prior and Barnes (2011: 264-265) assert in a previous issue of Social Policy \& Administration, the outcomes of social policy implementation processes have increasingly been explained as "the product of context-specific interpretations and negotiations shaped by agents' values, motivations and understandings" rather than as the result of a rational, goal-oriented process. Also Barrett (2004: 260) asserts this need for recognizing that policy is mediated, negotiated and modified during the implementation process, while addressing that we need to "invest in studies of implementation and change processes, both conceptual and empirical". In this strand of research, the interactions that occur between actors in the policy process, such as social administrators, and the construction of contextual and cultural meanings that those interactions generate, are a central focus (Prior and Barnes 2011).

Here, we inscribe our contribution into this recent tradition of social policy research while discussing the conceptual as well as empirical research findings acquired from a federal project in Belgium (see POD MI 2008, 2015a) as an interesting and relevant case for the ways in which anti-poverty policies are implemented. Since 2003, the federal project has employed service users with experience of poverty in federal public services in an attempt to increase the effectiveness, accessibility and quality of federal public service delivery (see POL MI 2006; Demeyer and Réa 2008). The rationale of the project refers to a concern that policies which affect the realization of welfare rights of certain groups, such as people in poverty, do not inherently lead to desirable outcomes (Bowpitt et al. 2014; Dean 
2013, 2015; Dwyer et al. 2015). This finding gels with research which has addressed the issue that not all welfare beneficiaries make effective use of available resources and opportunities, resulting in a selective take-up of social rights (Van Oorschot 1998). Moreover, this issue equally relates to current debates about the transformation of the welfare state to the 'enabling state', and the increasing emphasis on the individual responsibility of citizens and welfare recipients to be self-reliant and shape their own lives (Lorenz, 2005; Dean, 2015).

As a potential lever to provide effective, accessible and high-quality public services in Belgium in which the welfare rights of service users can be realized in practice, users with experience of poverty were trained as experts and employed as interpreters of the poverty problem in the administrations of these public policy units (Casman et al. 2010). This idea was originally developed in the Belgian National Action Plan (NAP) on Social Inclusion 2004-2006 and launched as an innovative project, coordinated by the Federal Public Service for Social Integration (POD MI) in Belgium (Roets et al., 2012). Being commissioned by the federal government to enhance and reinforce anti-poverty policies against the background of the EU-agenda on active inclusion of citizens, with reference to the importance of enabling (disadvantaged) citizens to become a full member of society, including having a job (Nicaise, 2012). Moreover, this particular project is implemented to bridge a so-called gap between people in poverty and those working in the administration of federal public policy units, being defined as "the lack of responsiveness of social administrators to poor service users" (Roets $e t$ al. 2012: 808). In the drive to become more responsive to the concerns of disadvantaged users, people with experience of poverty were employed in order to implement and monitor consumer-conscious anti-poverty strategies in public service delivery (see Beresford 2002; Gilliatt et al. 2000).

In a previous issue of Social Policy \& Administration (see Roets et al. 2012), while reporting about a first research evaluation of the project (see POD MI, 2008), we suggested that if a joint responsibility was established between people with experience of poverty and social administrators in challenging taken-for-granted practices, rather than perceiving employees with experience of poverty as so-called 'experts of the poverty problem' who had an individual responsibility in changing ineffective and inaccessible organizational dynamics, these institutional and collective dynamics actually embodied 
the opportunity to implement anti-poverty policies and strategies. More particularly, we argued that employing people with experience of poverty as exclusive 'expert interpreters' of the poverty problem in the administrations of these public policy units "may become an empty exercise, at best a token gesture or, at worst, a manipulative and exploitative exercise, for there is plenty of evidence here that simply establishing participatory structures and opportunities is no guarantee of their effectiveness (...) This implies that, if social policy wants to mobilize people with experience in poverty, the public policy units involved should develop elasticity in fundamentally transforming the power structure of the collective instead of empowering people in poverty to adapt to taken-for-granted practices" (Roets et al. 2012: 819). In that sense, we stressed that the challenge lies in enabling and establishing a collective responsibility and concern for the implementation of anti-poverty policies at an organizational level.

In this article, we consequently discuss the findings that were recently acquired from a second research evaluation of this project (see POD MI, 2015a). Elaborating on the findings of the first research evaluation (see POD MI, 2008), we aimed to gain more in-depth knowledge about the organizational dynamics in which this joint responsibility was actually established while exploring the perspectives of employees with experience of poverty and social administrators. In that vein, this challenge also concerns a complicated multi-level implementation issue, which implies that norms about quality of services are not only formulated at different levels but are also brought into practice by multiple actors (Aarons, et.al., 2009). As such, it is complicated for service users with experience of poverty to question or even challenge particular norms and to get a grip on these actors and their differing interpretations of these norms. Our main research question can be formulated as follows: how can we characterize the role and tasks of service users with experience of poverty in this implementation process with the aim of enhancing the quality and accessibility of public service delivery to citizens? In this second research evaluation, we borrowed insights from institutional theory (see DiMaggio and Powell 1983) as an interesting conceptual frame of reference that enabled us to develop knowledge about these organizational dynamics. We explore, more particularly, the concept of the 'institutional 
entrepreneur' (DiMaggio 1988; Battalina et al. 2009) to excavate how this particular anti-poverty policy strategy was implemented in federal public services as organizational contexts.

\section{An institutional theory framework}

Institutional theory has not only been applied in organizational studies (see for example Garud et al. 2007) but also gained much attention within Public Administration scholarship (Thoenig 2003; Frumkin and Galaskiewicz 2004; Rigg and O'Mahony 2013; Torfing and Sorensen 2014). In our contribution, institutional theory will help us to understand the functioning of a range of federal public policy units in Belgium. We substantiate the argument that these federal policy units, which are all active within the same institutional field, gradually adopt rather similar logics and routines for organizing their particular services to citizens. This process of institutionalization has, however, also hampered the use of and access to service delivery for citizens, and those living in poverty in particular.

For the purpose of this article, we will outline several key concepts of institutional theory while focusing on the development of 'institutions' and the quest for 'legitimacy' within institutional fields. Moreover, we will turn to the concept of the 'institutional entrepreneur', who can possibly operate as an agent of social agent in establishing a shared responsibility amongst social administrators within federal policy units, and in providing high-quality and accessible services for people living in poverty.

The development of institutions and the quest for legitimacy

Serving as a base for studying welfare organizations delivering services in fields such as health care, education or social work (Scott 2000; Sosin 2007; Villadsen 2013), institutional theory highlights the 
importance of norms, values and beliefs to explain the behavior and choices of organizations and actors that are active in the same field (Meyer and Rowan 1977; Villadsen 2013). As such, this theoretical framework enables us to move beyond a mere rational choice perspective when unraveling these contextual and cultural meanings because "institutions do not simply affect the strategic calculations of individuals, as rational choice institutionalists contend, but also their most basic preferences and very identity" (Hall and Taylor 1996: 948). In essence, institutional theory helps us to obtain a view on the positions of multiple constituents or organizations that are active in the same field (Meyer and Rowan 1977). These fields are generally understood as areas in which organizations interact on a regular basis, exchange information and knowledge and are, to some or a lesser extent, also dependent upon each other. Moreover, these fields are characterized by their own rules, regulations and forms of authority. As such, they could be considered as an external institutional environment in which socially defined norms occur and prescribe about how to behave in an efficient manner (Villadsen 2013).

Over time, these norms could also become 'institutionalized' as they are gradually established via sets of formal rules, programs for action and classification systems. This process of institutionalization gives rise to the formation of institutions, which serve as codes of appropriate behavior (March and Olsen 1989). As such, this refers to a process of a cognitive nature (Powell and DiMaggio 1991) through which members of an agency acquire values that go beyond the technical requirements of their organizational tasks (Selznick 1957). Institutions are then primarily associated with stability and setting out rules, beliefs and routines that describe and prescribe reality for organizations (Rigg and O’Mahony 2013) and could be seen as culturally embedded understandings, which explain what can be acted upon (Hoffman 1999) and even shape the imagination about alternative ways to behave (Thoenig 2003). In order to survive as an autonomous actor within a given institutional environment, it is argued that an organization should not only deliver good services or products but it must also appear legitimate by displaying a degree of conformity with the institutional environment with which it interacts (Thoenig 2003; Villadsen 2013). This is especially the case in fields in which organizations 
provide 'soft' services, such as education, culture or welfare provision, which are difficult to measure via an outcome-based evaluation (Villadsen 2013).

As previously argued, these processes of institutionalization can be related to the field of federal public policy units in Belgium and to the observed levels of selective take-up of social rights in particular. In order to substantiate this argument, we agree that institutions become taken for granted (Berger and Luckman 1967). As the transversally situated federal public service and initiator of the project in which service users with experience of poverty were deployed to improve the quality and accessibility of federal public service delivery, POD MI emphasizes that it is necessary "to detect and tackle hidden and taken-for-granted dynamics which result in the inaccessibility of public service delivery (...) and particularly prevent people in poverty in taking up their social rights" (POD MI 2015b: 10). Inspired by insights derived from institutional theory, this might be the case, since institutions help to provide some degree of stability and continuity with regard to organizational processes, and equally act as a particular lens or filter that permeates the organization and grants a specific, but also limited, rationality (Garud et al. 2007). Hence, when citizens appear on the radar, they must be fitted into programs for action and categories that are already embedded within the organization. Furthermore, it is rather unlikely that the problems and concerns of service users or citizens are seen in integral ways because the organization is only capable of showing interest in particular characteristics or ways of behaving (Scott 1995). As a result, we might observe a selective take-up of social rights, and problems with reference to a limited quality and inaccessibility of public service delivery.

\section{The institutional entrepreneur}

As we mentioned in the introduction, the implementation of a social policy through which users with experience in poverty were trained as experts and employed as interpreters of the poverty problem is perceived as a valuable anti-poverty strategy in the administrations of federal public policy units in 
Belgium (Casman et al. 2010). Applying insights derived from institutional theory (Villadsen 2013), it can be argued that this form of user participation can potentially contribute to challenging taken-forgranted practices in federal public services that cause a selective take-up of social rights. In that vein, we also use and apply the concept of the 'institutional entrepreneur' (DiMaggio 1988) to capture the roles and tasks of these users with experience in poverty. Indeed, theorizing their work and role in federal public policy units as so-called institutional entrepreneurs can offer a necessary dynamic perspective on policy implementation by highlighting processes of change instead of just focusing on aspects of continuity and stability. In essence, this idea enables us to reintroduce agency into the analysis of how power dynamics in organizations function within a given field or institutional context (Garud et al. 2007). As such, the aim is to avoid a perception of individuals as over-socialized and slavishly devoted to the reproduction of habits (Powell and Colyvas 2008). Nevertheless, the introduction of the concept of the institutional entrepreneur equally brings in the so-called 'paradox of embedded agency' (Holm 1995), which basically relates to the relationship between actors and their environments. This paradox refers to the tension between the fact that, on the one hand, norms and joint beliefs are institutionally determined and, on the other hand, human agency can cause and reveal institutional change in the environments of institutional entrepreneurs (Battalina et al. 2009). It therefore makes sense to explore the degrees of agency of institutional entrepreneurs when they are expected to challenge institutions and taken-for-granted practices (Battalina et al. 2009), while avoiding the creation of undesirable constructions of entrepreneurs as overly rational or totally disembedded agents who act as ‘heroes' (Meyer 2006).

In our research evaluation, we framed users with experience in poverty as institutional entrepreneurs, who can potentially act as "agents who initiate, and actively participate in the implementation of, changes that diverge from existing institutions, independent of whether the initial intent was to change the institutional environment and whether the changes were successfully implemented" (Battalina et al. 2009: 72). Such changes might be initiated within the boundaries of an organization or within the broader institutional context within which the actor is embedded, and might lead to the creation of yet 
other 'moral communities' (Thoenig 2003: 129) in which new expectations, behaviors, cultural values and beliefs are channeled and stabilized.

In that sense, this process of social change, as initiated by users with experience in poverty acting as institutional entrepreneurs, can take place when particular logics, beliefs or procedures are disrupted and others are valued and put forward (Lawrence et al. 2006). The main question in our research therefore focuses on whether the gradual diffusion of ideas and rationales, and especially those in which the perspective of people with experience of poverty themselves are included, actually gives rise to such new moral communities (Thoenig 2003) within an institutional field, and how this might lead to a shared responsibility in federal public policy units between users with experience of poverty and social administrators.

\section{Research context}

In this section, we provide additional information about the profile, training and recruitment of service users with experience of poverty who were employed in Belgian federal policy units.

Service users with experience of poverty were trained during an educational program that is organized by a private nonprofit organization in Belgium (see Spiesschaert, 2005; Casman et al., 2010). The target population consists of people who experienced what it is to live in poverty and were confronted with a complex web of financial, social, personal and relational problems. There are no additional conditions imposed (e.g. in terms of having already other diplomas) to potential participants. Furthermore, the 4-year program is part-time, free of charge and consists of two modules. Whereas the first year focuses on the personal recovery and emancipation of the participants, the next three years are very practice-oriented. The latter implies the training of communication skills and the opportunity to attend a trainee period within a nonprofit organization or public policy unit. The combination of this theoretical and practical approach enables the participants to transform their own experiences of living in poverty into expertise, which is defined as follows: "The key element consists of the fundamental difference between the position of an excluded person, who is forced to live in long-term exclusion and that of the organisations and participants in policy making, who are not familiar with this social 
experience nor with the harsh reality of the life of socially excluded people in all its aspects" (The Missing Link Europe 2011, our italics). It is claimed that the acquired experience and expertise enables them to formulate and identify relevant recommendations and concrete actions for helping to combat poverty in different organizational contexts.

After having successfully completed the training program, the participants receive an official certificate which allows them to be employed as a service user with experience in poverty within a private nonprofit organization or a policy unit at the federal (Belgian), the regional (Flemish) or local level. As outlined before, this article only builds on the findings acquired from a federal project. In this particular case, it was the POD MI, which is a transversal policy unit in the Belgian federal administration, that developed a coordination team. The coordination team acted as a catalyst to employ service users with experience of poverty in other federal policy units, where a social administrator was appointed as a 'buddy' to support the service user with experience of poverty within the organization. Moreover, the service user but also the buddy and the supervisor of the service in which these experts are employed are all supported by the coordinating team of the POD MI. Finally, it is important to notice that the POD also developed a general job profile consisting of three different roles to be performed by service users. Whereas the first role is about providing direct support to people living in poverty during their contacts with federal policy units (role 1), the second role is about the formulation of concrete proposition for enhancing the quality and accessibility of federal public service delivery (role 2). The last role relates to the initiation of critical reflections in the mind-set of fellow social administrators about the logics and images guiding their interaction with people living in poverty (role 3).

\section{Research methodology}


In order to gain an in-depth understanding of the organizational dynamics in federal public services during the implementation of this particular anti-poverty strategy, we adopted a qualitative and interpretative research approach in which knowledge is considered as situated, contextualized, and grounded in human activity (see Denzin and Lincoln 2003). Qualitative researchers are indeed concerned with process in their desire to discover how people negotiate meaning, while being interested in "what they are experiencing, how they interpret their experiences, and how they themselves structure the social world in which they live" (Bogdan and Biklen 1998: 7). Qualitative research is a relevant research strategy to study complex phenomena within their respective natural and social contexts, where the challenge for qualitative researchers implies that the subjective experiences of individuals are captured while the researcher attempts to see the world from the point of view of the research subjects (Roberts 2000). In what follows, we clarify the strategies employed in data collection and data analysis.

\section{Strategies of data collection}

This article draws upon findings from a research project of ten Belgian federal policy units. All service users ( 8 women and 2 men) who participated to this research were employed within their respective policy unit for at least one year, which allowed them to rely on a good understanding of their role and tasks. It is, however, important to notice that these service users might start from a slightly different position within these policy units. This mainly relates to the concrete service in which they are employed. In four of the selected policy units, the service users with experience of poverty do not have direct contacts with citizens or clients themselves. Instead, they are employed in a more general and transversal communication service of a policy unit (e.g. the overall recruitment service of federal government in Belgium, the federal policy unit focusing on economic development, etc.). Hence, their job enables them to have an important stake in both the internal and external communication of their policy unit towards its own social administrators, other public and private welfare actors and citizens or clients that are affected by the activities of the policy unit. 
The other six service users with experience in poverty are active in a federal policy unit that has a front office through which people might ask questions related to the social security system: about the fulfillment of their social rights, the calculation of their statutory pension, the payment of social security benefits related to parental leave, illness and invalidity, etc. Most often, the service users are employed in a back office, which also consists of graduate social workers. In situations related to poverty, the front line officers might decide to rely on the help of the back office and the service user with experience in poverty in particular. As such, these service users are able to have contact with citizens in a more direct and personal way.

To capture the social realities and processes of meaning-making in the federal public policy units, two complementary research methods were applied: ethnography, and qualitative interviews (see Denzin and Lincoln 2003; Bogdan and Biklen 1998). These research methods were appropriate to gain an indepth understanding on how the particular roles and tasks of users with experience of poverty were perceived and implemented when they gradually diffuse ideas in public policy units as institutional entrepreneurs. The ethnographic research approach served to make direct observations of how the roles and tasks of experts with experience of poverty were interpreted, and to get a grasp of how they possibly influenced their colleague-administrators on different levels of the 10 organizations under study. This information was complemented by ten semi-structured interviews (one interview in each federal policy unit). In each of these interviews, several people took part who were able to offer an indepth insight in the implementation process, such as the employed service user with experience of poverty, the buddy and/ or supervisor and some of their colleague-administrators. As a result, a total of 32 people participated in these interviews.

\section{Strategies of data-analysis}

The emerging research data were first fully transcribed (Peräkylä 2008). The combination of these research strategies strengthened and guaranteed the validity, reliability and saturation of the research 
process (Morse 2002). In order to analyse the collected data, a cross-analysis of the field notes and interviews was made. A directed approach to qualitative content analysis was then applied (Hsieh and Shannon 2005) as a method of qualitative data analysis that takes a volume of qualitative material to identify core consistencies and meanings (Myring 2000). The goal of a directed approach to content analysis is to validate and refine a conceptual framework or theory (Hsieh and Shannon 2005), which allows the researcher to examine key themes and meanings that may have been manifest or latent in the transcribed research data. More particularly, this approach served to apply and refine insights about how people with experience of poverty perform the three general roles that were described above. The main focus of the analysis embodies the question whether this form of user participation actually contributes to the ways in which institutional entrepreneurs effectively challenge and change power dynamics and institutionalized practices in federal public services that cause a selective take-up of social rights rather than reproduce taken-for-granted habits. According to our theoretical perspective, this process of social change can only take place when particular rationales and practices are disrupted and others are valued and implemented (Battilana et al., 2004).

\section{Research findings}

In this section, we discuss how the roles and tasks of users with experience of poverty within the federal policy units in which they are employed are interpreted and implemented.

Role 1 - Direct support of people living in poverty during their contacts with federal policy units 
As outlined before, some of the federal public policy units in which service users with experience of poverty are employed have a front office. The service users themselves are part of a back office. This implies that the role of front officer is primarily performed by social administrators who have a rich technical or legal expertise. There might, however, be situations in which the mutual understanding and communication between front officer and citizen is complicated. Most often, this relates to the situations of citizens who are confronted with a complex web of financial problems, difficulties related to their psycho-social well-being, unstable housing conditions, disturbed familiar relationships, etc. Hence, it might appear that citizens do not fully understand what is expected from them by a particular policy unit or launch questions for help or information that go beyond the scope of one single federal policy unit. This might trigger the front officer to seek assistance from his or her social service, where people with experience of poverty are employed. This is also reflected in the following quote from a social administrator:

"The decision to call in her (the expert with experience of poverty) help is always taken in an ad hoc manner ... still, I think we do not always have this reflex to question situations of the people who turn up at the front office more profoundly ... it is difficult to set out general guidelines, it is more a personal feeling about a situation”.

As a result, the service user with experience of poverty comes into play. In some cases, it is sufficient to give some extra clarification at the desk about what is expected from a person or to provide support for filling out a necessitated form. More often, however, the service user with experience of poverty will also take a moment to sit down with this person away from the context of the front office in which a sense of time pressure is always present. Our research findings show that their prior task is then to create a calm and stable environment and to provide a listening ear, which is important to unravel the different dimensions of the problems with which the person is confronted. If necessary, the service user with experience of poverty can decide to make an additional appointment at a later time, to do a home visit or to accompany a person during a visit to another public policy unit, housing company, social welfare organization, etc. 
Besides disentangling these sometimes complex requests for help, many service users with experience of poverty equally highlighted the importance of their direct support in clarifying what a particular federal policy unit can and cannot do. This is about correctly informing citizens who face huge difficulties in understanding the fragmented way in which federal public service delivery, and social welfare provision in general, is currently organized. In that vein, it has been repeatedly stated that citizens, and especially those living in poverty, step into a front office without much prior knowledge. Nevertheless, they often display an expectation that all issues at stake could be immediately tackled. Hence, by outlining that it is necessary to undertake other steps, the service user with experience of poverty is able to eliminate some of the frustrations experienced by citizens who do not feel properly helped or understood.

In sum, this role is about the direct support provided to citizens by the users with experience of poverty themselves. Moreover, we equally outlined that the opportunity for social administrators to call in the help of a user with experience of poverty might make them more responsive vis-à-vis situations of citizens as well. This is because they could gradually develop a reflex to make a personal assessment of these situations and to capture relevant signals when interacting with people living in poverty. Although these practices are valuable to initiate some change in the mind-set of social administrators, they do not suffice yet to install a real shared responsibility for enhancing the quality and accessibility of public service delivery. Therefore, we must further explore the additional roles of users with experience of poverty and their interactions with fellow social administrators.

Role 2 - Formulating concrete propositions for enhancing the quality and accessibility for citizens of the services performed by their federal policy unit

These direct experiences and observations when assisting people living in poverty (also see role 1) do provide fertile ground for many users with experience of poverty to get a more general sense of the financial, administrative, cultural, etc. thresholds that might restrict the use of, and citizens' access to, 
the services provided by their respective federal public policy units. Nevertheless, this second role is also performed by the service users that do not directly interact with citizens via a front office. Starting from their own experiences, observations and frustrations, they are able to unravel particular thresholds (e.g. in terms of availability or accessibility of services) and to enhance the comprehensibility of the information that is provided to citizens by their policy unit. Hence, by making concrete suggestions for adapting the style, content or tools for communication vis-à-vis citizens or for re-thinking internal procedures, service users with experience of poverty equally improved the overall quality and accessibility of the public service delivery. In the following paragraphs, we will substantiate this particular argument by outlining two concrete examples that emerged from our research.

A first example relates to the excessive use of administrative and judicial language by federal policy units when communicating with citizens. This lack of a shared vocabulary severely disturbed the interaction and mutual understanding between social administrators and citizens who presented themselves to a front office. This is reflected in the following quote of a user with experience of poverty:

"Many citizens express their frustrations as they are not able to fully understand what was expected from them. They do not always have the skills or prior knowledge to comprehend this professional terminology”.

We observed many occasions on which the service users with experience of poverty warned their federal policy units about the negative consequences of the often unintended use of technical jargon, not only in individual contacts with service users, but in many of the cases in which they were involved. In essence, this could reduce the comprehensibility of the communication and the messages that are transferred to citizens, and to people living in poverty in particular.

Hence, besides providing direct and individual support for citizens at the front office (see also role 1), service users with experience of poverty aimed at changing the style and content of the communication in more general ways as well. For example, a service user with experience of poverty made a short 
film that was uploaded to the front page of the website of his policy unit. This film provided a short and comprehensible introduction about the functioning of his policy unit and about the role he could perform in assisting and reassuring people in their contacts with this public service. Furthermore, several other service users with experience of poverty stressed the need to revise the information brochures that were distributed in the waiting room of the front office. This could be illustrated in the following way:

"Some persons face difficulties in understanding the language due to illiteracy or a different cultural background. Therefore, I promoted the use of images, icons or symbols on posters to enhance the comprehensibility of the communication".

A second example implies the proposition of service users with experience of poverty to revise an administrative procedure. More particularly, this procedure refers to the way in which a citizen receives a request to present himself to an office of a federal policy unit to fulfill a legal or administrative requirement to retain his financial benefit. Until recently, this request was uniquely sent via an official letter to the latest known home address. If the person did not show up for the appointment, a second letter was sent to that same address. A second absence was then interpreted as a refusal and eventually led to the suspension of the person from the system, and consequently to a nontake-up of their social rights.

The service user with experience of poverty then started to re-establish the contact with these people who had been suspended. It appeared that some of them did not have a stable housing situation or were not familiar with handling their personal administration. Moreover, they indicated a preference to be contacted via a phone call to make an immediate appointment. Based upon his contacts with these people who were excluded from receiving the support to which they were entitled, the service user with experience of poverty commenced to communicate his findings to the head of his department and his colleagues. This eventually led to the adaptation of a new procedure within this particular federal policy unit as people could indicate themselves whether they preferred being contacted by letter or by phone. 
In sum, the formulation of concrete propositions to revise internal procedures or style of communication are levers to enhance the overall quality and accessibility of public service delivery within particular policy units. More importantly, however, it might also contribute to raising awareness amongst social administrators of these policy units about thresholds and to deepen their understanding of the train of thought, rationales and experiences of people living in situations of poverty. This will be further outlined in the next paragraphs.

Role 3 - Initiating a critical reflection in the mind-set of fellow social administrators about the logics, evidences and images guiding their interaction with people living in poverty

In this section, it is argued that the first two roles are necessary steps to perform a third role, which is related to the initiation of critical reflections in the mind-set of fellow social administrators about the logics and evidences guiding their interaction with people living in poverty. Hence, by providing a good example when carrying out supportive actions in individual contacts (see also role 1) and by suggesting concrete propositions to avoid or eliminate multiple thresholds to services of federal policy units on a more collective level (see also role 2), users with experience of poverty are able to diffuse 'new' information or 'other' insights to their fellow social administrators. This will generate both formal and informal dialogues between these actors about the particular routines, rationales, procedures and programs for action that are taken-for-granted and through which the interaction with citizens is steered. In our view, this process of contemplation, which is mostly associated with the third role, is an indispensable factor in creating a real shared responsibility with regard to the situations of people living in poverty. This is because it generates social change that does not entirely depend upon the presence and continuous effort of the service users with experience of poverty themselves. Therefore, it is only by combining these three roles that service users with experience of poverty could be considered as real institutional entrepreneurs who act as agents of change by 
initiating and actively participating in the implementation of changes that diverge from existing institutions and routines within their respective policy units.

Nevertheless, it must be acknowledged that there is no such thing as a 'manual' or a 'procedural way' for service users with experience of poverty to perform this third role or to install a shared responsibility with social administrators for dealing with social exclusion. Moreover, the process of initiating this critical reflection about the rationales and routines incorporated by social administrators seems to be a rather gradual and precarious practice. This implies that it will, to some or a lesser extent, also be situation-driven. Hence, although there is no fixed moment or pre-structured way to determine whether a 'change' has occurred, it is still possible to give some concrete examples that might help us to illustrate the levers and obstacles to initiating and perpetuating these reflective processes.

It was, for example, acknowledged by all service users with experience of poverty that the presence of stereotypes with regard to people living in poverty was a persistent problem within their respective federal policy units. This feeling has been expressed by service users with experience of poverty in the following way:

"I must regularly try to adjust the image of my colleagues about being poor. After all, 'the poor person' does not exist. Therefore, this requires that I have to make visible a diversity of problems and situations. Many people are not really poor but still, they are just one or two setbacks away from ending up in a really bad situation".

Another service user with experience of poverty added:

"I can imagine the frustrations of some of my colleagues at the front office when they are confronted with irregularities. Social fraud is never allowed and must be penalized ... Still, I regret that this urges them to label very different kinds of situations too rapidly as social fraud. As such, other people could become unjustly stigmatized". 
Furthermore, it was observed during the research that social administrators frequently admitted the risk of speaking out on behalf of citizens themselves. This idea of "knowing best what needs to be done' was also apparent with regard to particular situations of people living in poverty. This can be illustrated by a quote from a social worker who is active in a federal hospital that temporarily accommodates and supports people with mental health problems. In this hospital there is also a service user with experience of poverty who assists the social service:

"We are used to thinking in terms of being active ... Hence, I could not understand why a person who stayed in our facility chooses to stay in his room for the whole day without taking any action at all ... I always believed that our daytime activities had a low threshold. She (the service user with experience of poverty), however, explained to me that people living in poverty are often too ashamed to admit that they do not understand something or that they cannot follow the pace of others. As such, they might prefer to be alone".

The example above highlights the importance of raising an awareness about particular rationales and routines that are often taken-for-granted within policy units but that lead, however, to some form of social exclusion. Yet, this reveals an important question about the way in which service users with experience of poverty can position themselves vis-à-vis their fellow social administrators. The way in which colleagues are approached and confronted with the consequences of their choices and behavior is indeed a very delicate and rather complicated process. Hence, many service users with experience of poverty are aware of the difficulties associated with the need to find the 'right tone' to address colleagues. This is also reflected in the following quote from a service user with experience of poverty:

"During my early years, I deliberately positioned myself against the others. I was a lone fighter who wanted to convince my colleagues. My style was ... too attacking. By trial and error, I learned to communicate with them ... Still, until today, this bad start hampers the way in which I can interact with some of my colleagues". 
Hence, instead of initiating a dialogue with his colleagues, there appeared to be very much 'resistance' vis-à-vis the service user with experience of poverty and his message. Therefore, it is important to highlight some of the levers that are used by service users with experience of poverty to perform a role in initiating critical reflections about particular rationales and taken-for-granted practices within federal policy units and in implementing a joint responsibility.

One service user with experience of poverty explained that he had been positioned in a low-profile role within his policy unit, which enabled him to get to know his colleagues and the language and procedures they were using to perform their jobs. Moreover, he acknowledged the relatively slow and cyclical character of his task to establish some kind of dialogue with colleagues. He phrased it as follows:

"Like a priest, I do not need two bibles to build up my message. My message is clear, I just have to repeat it over and over again, and if necessary, to wrap it up in different ways".

Furthermore, it is important to notice that, over time, these contacts with colleagues are often established in a rather informal and casual way in everyday interactions. As such, many of the service users with experience of poverty indicated that they performed a role as a sounding board for fellow colleagues. This is because social administrators equally started to share their experiences vis-à-vis particular service user situations with the aim of providing some feedback on the way they handled a situation. This paved the road for a conversation about some of the tensions and dilemmas with which social administrators were confronted when interacting with service users, and people in poverty in particular. Hereby, the employed service users with experience of poverty might find and create an opportunity to make a further appeal to the empathy and interests of social administrations with regard to situations of poverty. In the following paragraph, we might get more insight about this informal process. It is about a situation in which a social administrator became frustrated because a woman, who mainly spoke Arabic, did not succeed in understanding what he tried to explain to her during a contact at the front office. Hence, the service user with experience of poverty stressed the need to remain sensitive to rephrase a message if this appears to be necessary. 
"Recently, I asked a colleague about what he would do if he moved to the United States without speaking English. He agreed that he would be grateful that someone at a front office made an effort to help him".

\section{Concluding reflections}

In this article, we aimed to unravel the way in which the quality and accessibility of public service delivery were enhanced through the introduction of a shared responsibility within public policy units with regard to the situations of people living in poverty. We focused specifically on examining the potential roles of users with experience of poverty, who were trained as experts and employed as interpreters of the poverty problem in federal public policy units in Belgium.

Starting from insights of institutional theory about the development of 'institutions' and the quest for 'legitimacy' within institutional fields, it was argued that service users with experience of poverty could be considered as 'institutional entrepreneurs' who might act as agents of social change by uncovering thresholds to public service delivery, by challenging taken-for-granted practices that led to social exclusion, and by gradually installing a shared responsibility within policy units for tackling a selective take-up of social rights.

Nevertheless, in order for a person to become a real institutional entrepreneur, our analysis shows that although these roles could be considered as relatively autonomous subjects of analysis, there should be a necessary synergy between them. Hence, in order to act as institutional entrepreneurs in challenging taken-for-granted practices, users with experience of poverty must, to a greater or lesser and alternating extent, perform all three roles. This implies that the simple fact of providing direct support to people living in poverty during their contacts with a federal policy unit (role 1) or formulating concrete propositions for enhancing the quality and accessibility of federal public service delivery (role 2) does not suffice to install a shared responsibility within policy units vis-à-vis situations of 
people living in poverty. On the contrary, however, it is also rather unlikely to suppose that users with experience of poverty should be capable of directly initiating a critical reflection in the mind-set of social administrators (role 3) without establishing a solid base for fruitful interaction and (in)formal communication between themselves and social administrators. As a result, we state that the first two roles are also necessary in paving the road to perform the third role. This finding entails that the synergy between the different roles of service users with experience of poverty should be embraced. Whereas some of them provided direct support to citizens during their contacts with federal public policy units (role 1), all service users were able to launch concrete propositions for revising procedures, communication, etc. within their respective policy units based on these direct contacts or their own personal experiences (role 2). In our view, it does not, however, suffice that the service users with experience of poverty perform one of these first two roles (or a combination of both) to install a shared responsibility within public policy units. After all, our research shows that social change is only generated when the desired change does not mainly depend upon the presence and individual efforts of service users with experience of poverty themselves. Such dynamics in federal public services eventually lead to an undesirable construction of service users with experience of poverty who act as some kind of 'hero' in changing these institutional logics, routines and beliefs (Battilana et al. 2009). As a consequence, this hampers a transformation of the existing power structure of federal public policy units (Roets et al. 2012)

In that vein, we highlighted several examples of situations in which the diffusion of 'new' information or insights by the service users with experience of poverty generated (in)formal dialogues between themselves and social administrators about the routines, rationales and programs for action through which interaction with citizens was guided. This synergy between the three roles was associated with how a critical reflection was initiated in the mind-set of fellow social administrators about thresholds and taken-for-granted practices, which were present within their policy units and hampered the quality and accessibility of public service delivery for people living in poverty (role 3). As a result, many service users were indeed able to perform a role as institutional entrepreneurs and achieved tangible 
and long-term structural, organizational and institutional change within their organization (e.g. the modification of internal procedures and style of communication).

\section{References}

Aarons, G.A., Hurlburt, M. \& Horwitz, S.M (2011), Advancing a Conceptual Model of EvidenceBased Practice Implementation in Public Service Sectors, Administration \& Policy in Mental Health Services Research, 38, 4.

Barrett, S. M. (2004), Implementation studies: time for a revival? Personal reflections on 20 years of implementation studies, Public Administration, 82, 2: 249-62.

Battalina, J., Leca, B. and Boxenbaum (2009), How actors change institutions: Towards a theory of Institutional Entrepreneurship, The Academy of Management Annals, 3, 1: 65-107.

Beresford, P. (2002), Participation and social policy: transformation, liberation or regulation? In R.

Sykes, C. Bochel and N. Ellison (eds), Social Policy Review 14: Developments and Debates 20012002, pp. 265-87, Bristol: Policy Press.

Berger, P., and Luckmann, T. (1967), The social construction of reality, London: Penguin.

Bogdan, R. C. and Biklen, S. K. (1998), Qualitative Research for Education: an Introduction to Theory and Methods. Boston: Pearson.

Bowpitt, G., Dwyer, P., Sundvin, E. and Weinstein, M. (2014), Places of sanctuary for 'the undeserving'? Homeless people's day centres and the problem of conditionality, British Journal of Social Work, 44: 1251-1267. 
Casman, M. Th., Vranken, J., Dierckx, D., Deflandre, D. and Campaert, G. (2010), Experts by Experience in Poverty and Social Exclusion. Innovation Players in the Belgian Federal Public Services, Antwerp: Garant.

Dean, H. (2013), The translation of needs into rights: reconceptualising social citizenship as a global phenomenon, International Journal of Social Welfare, 22, 1: 32-49.

Dean, H. (2015), Social rights and human welfare. London: Routledge.

Denzin, N. and Lincoln, Y. (2003), The Landscape of Qualitative Research: Theories and Issues. London: SAGE.

Demeyer, B. and Réa, A. (2008), Eindrapport Evaluatie ESF-project 'Ervaringsdeskundigen in Armoede en Sociale Uitsluiting binnen de Federale Overheidsdiensten', Onuitgegeven Onderzoeksrapport Katholieke Universiteit Leuven, Leuven: Hoger Instituut van de Arbeid (HIVA).

DiMaggio, P. J. and Powell, W. W. (1983), The Iron Cage revisited: institutional isomorphism and collective rationality in organizational fields. American Sociological Review, 38, 2: 147-160.

DiMaggio, P. J. (1988), Interest and Agency in Institutional Theory, In L. Zucker (ed), Institutional Patterns and Organizations, pp. 3-21, Cambridge: MA. Ballinger.

Dwyer, P., Bowpitt, G., Sundin, E. and Weinstein, M. (2015), Rights, responsibilities and refusals: homelessness policy and the exclusion of single homeless people with complex needs. Critical Social Policy, 35, 1: 3-23.

Frumkin, P. and Galaskiewicz, J. (2004), Institutional isomorphism and public sector organizations, Journal of Public Administration Research and Theory, 14, 3: 283-307.

Garud, R., Hardy, C. and Maguire, S. (2007), Institutional entrepreneurship as embedded agency: An introduction to the Special Issue, Organization Studies, 28, 7: 957-969. 
Gilliatt, S., Fenwick, J. and Alford, D. (2000), Public services and the consumer: empowerment or control? Social Policy \& Administration, 34, 3: 333-49.

Hall, P., A. and Taylor, R. (1996), Political science and the three new Institutionalisms. Political Studies, 44, 5: 936-957.

Hoffman, A. J. (1999), Institutional evolution and change: Environmentalism and the US chemical industry, Academy of Management Journal, 42: 351-371.

Holm, P. (1995), The dynamics of Institutionalism: transformation processes in Norwegian fisheries, Administrative Science Quarterly, 40: 398-422.

Hsieh, H. F. and Shannon, S. E. (2005), Three approaches to qualitative content analysis, Qualitative Health Research, 15, 9: 1277-1288.

Lawrence, T. B. and Suddaby, R. 2006, Institutions and Institutional Work. In S. R. Clegg, C. Hardy, T. B. Lawrence, \& W. R. Nord (Eds.) Handbook of organization studies, 2nd Edition, pp. 215-254. London: Sage.

Lorenz, W. (2005). Social work and a new social order: Challenging neo-liberalism's erosion of solidarity. Social Work \& Society, 3 (1), 93-101.

March, J.G. and Olsen, J.P. (1989), Rediscovering Institutions. New York: Free Press.

Meyer, J.W. \& Rowan, B., (1977), Institutionalized organizations: Formal structure as myth and ceremony, American Journal of Sociology, 83, 2: 340-363.

Meyer, R.E., (2006). Visiting Relatives: Current Development in the Sociology of Knowledge, Organization, 13(5): 725-738.

Morse, J. M. (2002), Enhancing the usefulness of qualitative inquiry: Gaps, directions, and responsibilities, Qualitative Health Research, 12, 10: 1419-1426

Myring, P. (2000), Qualitative content analysis, Forum Qualitative Social Research, 1,2:1-10. 
Nicaise, I. (2012), A Smart Social Inclusion Policy for the EU: the role of education and training, European Journal of Education, 47, 2, 327-342.

Pache, A-C. \& Santos, F. (2013), Inside the hybrid organization: selective coupling as a response to competing institutional logics, Academy of Management Journal, 56, 4: 972-1001.

Peräkylä, A. (2008), Analyzing Talk and Text. In N. K. Denzin \& Y. S. Lincoln (red.), Handbook of qualitative research. pp. 869-886, London: SAGE.

Powell, W. W. and J. A. Colyvas. 2008,. Micro-foundations of Institutional Theory. In R. Greenwood et al. (Ed),, Handbook of Organizational Institutionalism, pp. 276-98. London: Sage.

Prior, D. and Barnes, M. (2011), Subverting social policy on the front line: agencies of resistance in the delivery of services, Social Policy \& Administration, 45, 3: 264-279.

Villadsen, K. (2013), Neo-institutional theory: myths and legitimacy, In N. Mik-Meyer \& K. Villadsen (Eds.), Power and Welfare: understanding citizens' encounters with state welfare. New York: Routledge.

POD MI (2008), Evaluatie ESF-project Ervaringsdeskundigen in armoede en sociale uitsluiting binnen de federale overheidsdiensten (Final Report), Brussels: POD MI.

POD MI (2015a), Evaluatie van de inzet van ervaringsdeskundigen in de federale overheidsdiensten (Final Report). Brussels: POD MI.

POD MI (2015b), Ervaringsdeskundigen: (ver)bouwgids voor een modern overheid. Brussels: POD MI.

Powell, W. W. and DiMaggio, P. J. (1991), The new institutionalism in organizational analysis, Chicago : University of Chicago Press.

Rigg, C. and O'Mahony, N. (2013), Frustrations in collaborative working, Public Management Review, 15 1: 83-108. 
Roets, G., Roose, R., Bouverne-De Bie, M., Claes, L. and Van Hove, G. (2012), Pawns or Pioneers? The logic of user participation in anti-poverty policy making in public policy units in Belgium, Social Policy \& Administration, 46, 7: 807-822.

Scott, R. (1995), Institutions and Organizations, Thousand Oaks, CA: Sage.

Selznick, P (1957), Leadership in Administration, New York: Harper \& Row.

Spiesschaert, F. (2005), Ervaringsdeskundige in Armoede en Sociale Uitsluiting: Een Inleiding tot de Methodiek, Leuven/Voorburg: Acco.

Thoenig, J-C. 2003, Institutional Theories and Public Institutions: Traditions and Appropriateness. In G. Peters and J. Pierre (Eds.), Handbook of Public Administration, London: SAGE Publications.

Torfing, J. and Sorensen, E. (2014), The European debate on governance networks: Towards a new and viable paradigm?, Policy and Society, 33, 4: 329-344.

Van Oorschot, W. (1998), Failing selectivity: On the extent and causes of non-take-up of social security benefits. In H.-J. Andress (Ed.), Empirical poverty research in a comparative perspective, pp. 101-130. Aldershot, Ashgate. 